\title{
The Microstructure of the Cultured Freshwater Pearl
}

\author{
L.E. MURR ${ }^{1,2}$ and D.A. RAMIREZ ${ }^{1}$ \\ 1.-Department of Metallurgical and Materials Engineering, University of Texas at El Paso, \\ El Paso, TX 79968, USA. 2.—e-mail: lemurr@utep.edu
}

\begin{abstract}
Pearls are composite materials of calcium carbonate polymorphs (calcite and aragonite) and organic macromolecules (polysaccharides and proteins) which contain genes and transcription factors that direct the formation of calcite and aragonite polygonal tiles, including their shape, size, and geometrical accommodation. These biologically derived instructions are transmitted from donor mussel shell mantle tissue by inserting seed grafts into freshwater production mussels. In this paper the internal and external freshwater pearl structure for the cultured triangle mussel Hyriopsis cumingii is examined by light optical microscopy, scanning electron microscopy, and x-ray diffraction. Pearl interior crystal structure evolves as mainly concentric calcite tile layers from the seed sac, with mixtures of aragonite polygonal (hexagonal-like) tiles. Within about $0.8-1 \mathrm{~mm}$ from the ideal (curved) pearl surface, the aragonite tiles form as continuous, overlapping layers 300-400 nm thick, with interlamellar organic material.
\end{abstract}

\section{INTRODUCTION}

Pearls are produced by all shell-bearing mollusks, including oysters and mussels. The shell, composed of complex calcium carbonate $\left(\mathrm{CaCO}_{3}\right)$ and organic (polymer) composites, has essentially two layers: an outer, often chalk-like prismatic calcite layer and an inner, pearly, nacreous layer referred to as mother of pearl. This inner layer is primarily aragonite, but it often contains intermixed crystals of calcite. The calcitic polymorph of $\mathrm{CaCO}_{3}$ has a trigonal (rhombic or rhombohedral) crystal structure (sometimes referred to as trigonal hexagonal) with space group R3C, and lattice parameters $a=0.499 \mathrm{~nm}$ and $c=1.706 \mathrm{~nm}$. The aragonitic polymorph of $\mathrm{CaCO}_{3}$ has an orthorhombic crystal structure with space group $\mathrm{D}_{2 \mathrm{H}}^{16}-P m c n$ (or $2 \mathrm{~m} / 2 \mathrm{~m} / 2 \mathrm{~m}$ ) and lattice parameters $a=0.496 \mathrm{~nm}, b=0.797 \mathrm{~nm}$, and $c=0.574 \mathrm{~nm}^{1}$ The common model for the inner nacreous layer (or mother of pearl) is uniformly thick layers (perpendicular to the $c$-axis) composed of tablets or tiles of mostly hexagonal, polygon-shaped aragonite crystals about 5-15 $\mu \mathrm{m}$ in diameter ${ }^{2}$ separated by interlamellar layers of organic (conchiolin) matrix. This matrix consists of macromolecules such as the polysaccharide $\beta$-chitin, a relatively hydrophobic silk protein, and a complex assemblage of other hydrophilic proteins. ${ }^{3-5}$ The aragonite tile layers are $300-500 \mathrm{~nm}$ thick, while the organic layers are $\sim 20-50 \mathrm{~nm}$ thick and are considered to serve as a binder for the aragonite tile layers to form a block-and-mortar hierarchical structure exhibiting characteristically high strength and hardness. ${ }^{5-9}$ Compressive strengths vary from about $300 \mathrm{MPa}$ to $500 \mathrm{MPa}^{9}$

Over 100,000 living species bear a shell, ranging from a single valve to eight overlapping calcareous valves. ${ }^{10}$ There are roughly 1000 species of mussel bivalves worldwide: a bivalve shell is composed of two hinged valves joined by a ligament. Three hundred mussel species inhabit freshwater rivers, streams, and lakes in the USA, the richest diversity of pearlproducing mussels in the world; for example, between 1989 and 2001, southeastern rivers in Kansas were commercially harvested for more than 2 million pounds of mussel shells for export trade, and Texas freshwater mussels have been harvested for decades, mostly for cultured pearl production in China, which today is the only commercial producer of freshwater pearls. Dozens of other US states have harvested freshwater mussel shells over the past century for mother-of-pearl inlay, buttons, and cultured pearl production, especially Japanese cultured pearl production in the middle of the 20th century [see, for example, pearl-guide.com; jsbeads.com/Freshwaterpearls; US Fish and Wildlife Service (fws.gov), and many other web sites]. 
Pearls are complex, multilayered, concentric structures mimicking mother of pearl or the part of the mussel (mollusk) anatomy called the mantle. The mantle edge secretes the organic framework which controls the formation of the calcium carbonate crystals: their nucleation, growth, polymorphic structure, and even the positioning and elongation of crystal polygons within the concentric layers, and in the surface region which defines pearl quality. ${ }^{11-13}$ Pearl formation involves a number of biological genes and transcription factors which are part of the organism's DNA-derived modeling software. ${ }^{14}$

Unlike natural pearl production, which results by the mollusk's response to an irritant (such as a fine sand grain) which acts as a nucleating agent, cultured freshwater pearls are nucleated by inserting (or seeding) a roughly $3 \mathrm{~mm}$ square of mantle tissue (a tissue graft) cut from a suitable donor mussel, initially in 3-mm-wide strips. These seeds are inserted into each shell valve, which normally accepts from 12 to 16 such grafts or seeds. The organism responds to this "irritant" by enclosing it in a cystic tissue sac upon which concentric ring-shaped layers of irregular, polymorphic, prismatic calcium carbonate, and conchiolin propagate layer by layer. Cultivation of contemporary Chinese freshwater pearls normally requires $2-4$ years, during which time pearl sizes can range from $1 \mathrm{~mm}$ to $11 \mathrm{~mm}$, with an average of 20 pearls produced in each mussel. The current mussel of choice is the triangle shell mussel Hyriopsis cumingii, or related hybrids. The majority of Chinese freshwater pearls are produced using this mussel in lakes and ponds in Zheijiang Province, which produced around 1500 tons of freshwater pearls in 2005, about $73 \%$ of the world freshwater pearl market. The largest freshwater pearl marketplace is Zhuji City, the capital of Zheijiang Province, located $200 \mathrm{~km}$ from Shanghai and $60 \mathrm{~km}$ from Hangzhou. Often referred to as "Pearl City," there are more than 2400 show rooms in mall-like complexes forming the largest pearl marketplace in the world, having a value near US $\$ 3$ billion.

While there have been decades of studies directed toward elucidating the microstructural features of mother of pearl in a wide range of mollusk shells as indicated briefly above, there are few comparable studies of contemporary freshwater pearl microstructures for Hyriopsis cumingii cultivated pearls. In this study we utilized light optical microscopy (LOM), scanning electron microscopy (SEM), and x-ray diffraction (XRD) to examine the calcium carbonate polymorphic crystal structures and morphologies composing the internal, concentric ring structures and the outer freshwater pearl surface structure.

\section{EXPERIMENTAL PROCEDURES}

Freshwater pearls harvested from Hyriopsis cumingii mussels cultivated in ponds in Zhuji City, China were utilized in this study. Figure 1 illustrates the harvested, triangle mussel measuring from $12 \mathrm{~cm}$ to $16 \mathrm{~cm}$ in length. These mussels are normally suspended in relatively shallow ponds from marked stakes or posts to which they are tied to prevent them from sinking into the mud. Figure 2 shows a typical pond with marked stakes which allow systematic harvests of the pearl-containing mussels (Fig. 1). Freshwater pearl harvests are usually purchased while still in the shell (Fig. 1). Upon removal of the pearls, the valve tissue is dried and used for fertilizer or duck food, while the shells revert to pearl inlay and button production, seed strip production, or are crushed for calcium carbonate product development. Pearls rejected for the jewelry or gem market are crushed to powder and used in a variety of medicinal or related products, including creams and ointments. This is a quintessential example of by-product synergism.

In the first stage of pearl recovery, they are cleaned and sorted by size, shape, and color. There is a large market for shape and color mixtures as illustrated in Fig. 3. In some cases pearls are bleached to assure no color, while in some cases pearls are also colored using dyes or radiation. There is, however, a large market for naturally colored freshwater pearls, which are illustrated in Fig. 3. Pearls are drilled and polished with cornmeal and wax. They are then matched into temporary strands of the same size or size and shape.

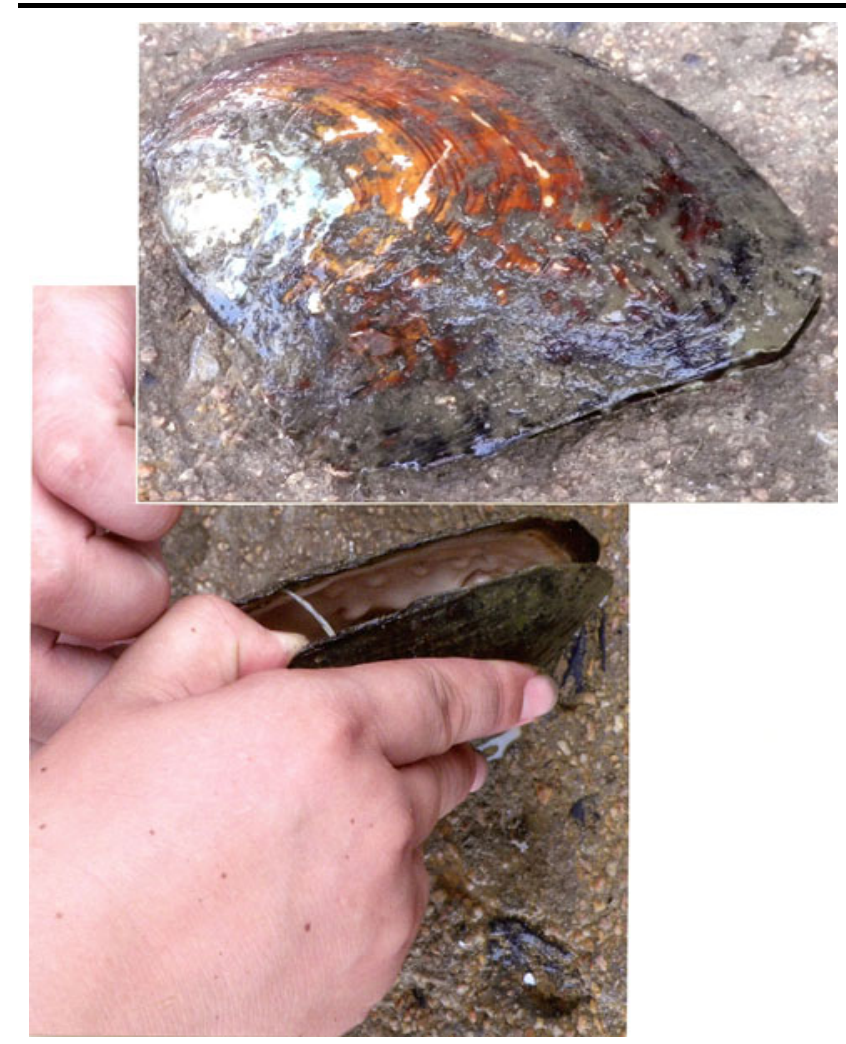

Fig. 1. Cultivated triangle shell mussel (Hyriopsis cumingii) ready for freshwater pearl harvest. Lower left insert shows opening of bivalve shell (Color figure online). 


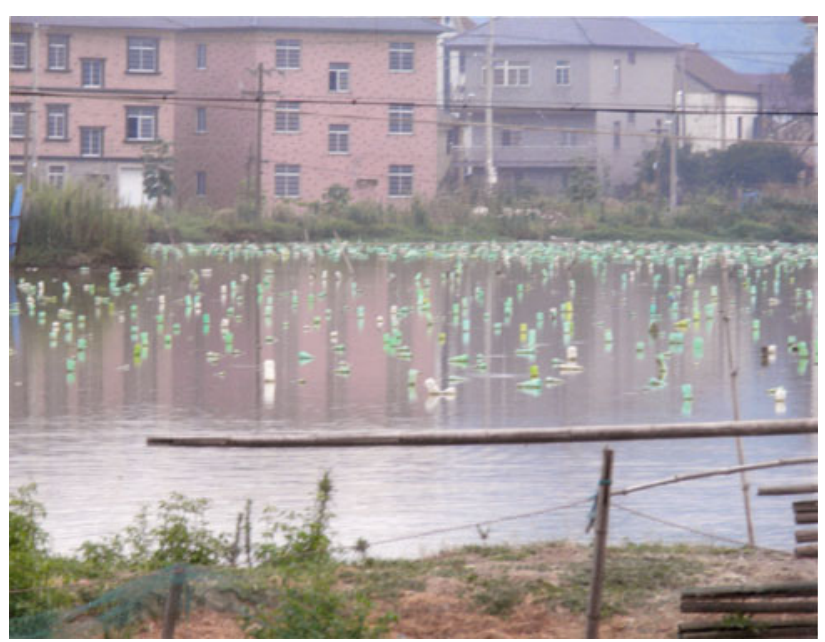

Fig. 2. Freshwater pond with mussel identification stakes in Zhuji City, Zheijiang Province, China.

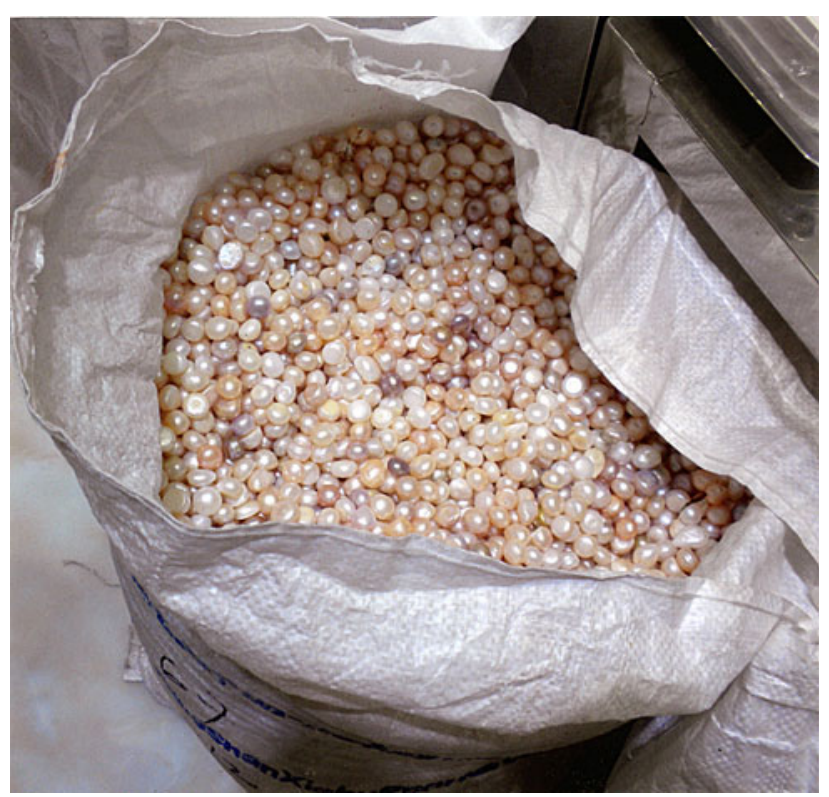

Fig. 3. Partially sorted mixture of freshwater pearl shapes and colors (Color figure online).

In addition, strands of specific color or mixed color are also matched, but there is also a wide market for unmatched sizes and colors, and these variations are also utilized in the strands. These strands are called hanks, usually being bundled into 5-10 temporary strands as wholesale products.

We examined numerous large pearls $(9-11 \mathrm{~mm}$ diameter) in this study, including half-sections from fractured pearls resulting during hole drilling. In addition to LOM, we used a high-resolution (14 Gb) digital camera with a zoom lens for imaging the internal concentric, structural rings because the wavelength sensitivity could produce enhanced or exaggerated colors characteristic of structural color resulting by diffraction from the crystal layer

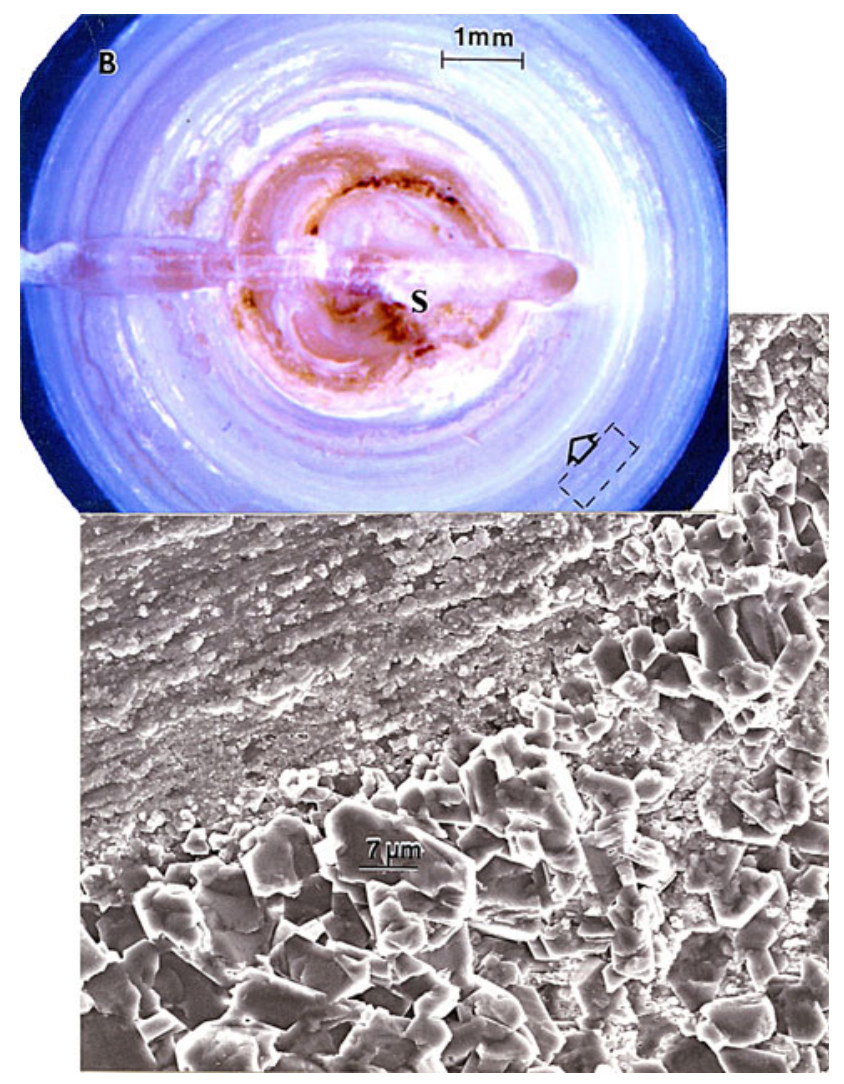

Fig. 4. Nearly perfectly spherical freshwater pearl cross-section created by drill fracture showing more than 30 concentric layers around the seed/sac(s). The exaggerated colors, primarily shades of blue, provide some evidence for crystal structures favoring the 300 $500 \mathrm{~nm}$ size regime. White bands imply random or large sizes $(>1 \mu \mathrm{m})$. The dark-blue (B) layer $(\sim 100 \mu \mathrm{m}$ thick) at the surface portends $\sim 400 \mathrm{~nm}$ wavelength. Dotted enclosure and arrow in SEM insert indicate layer of random calcite crystal polygons (hexagonal) (white) and much smaller, random calcite crystals diffracting very light blue (Color figure online).

dimensions and regularity. In addition, the internal and external pearl structures were observed in a Hitachi S-4800 field-emission SEM operating at $20 \mathrm{kV}$ in secondary emission mode. The SEM was also fitted with an EDAX energy-dispersive (x-ray) spectrometer (EDS). XRD analyses were also conducted using a Brucker Discover XSX-D8 XRD system employing a copper target to produce a characteristic x-ray wavelength of $0.154 \mathrm{~nm}$. This system employed a laser beam surface locator which allowed the irradiated area on the pearl surface to be identified.

\section{Cultured Pearl Structure Evolution}

Figure 4 shows a drill-fractured spherical pearl interior including the roughly $3-\mathrm{mm}$ seed/sac region which nucleates the multi-concentric-layered pearl. Color enhancement clearly shows a propensity of blue-wavelength structure emanating from the central seed graft region (S) in Fig. 4, with the most intense blue near the pearl surface at " $B$ ". The dotted area with arrow in Fig. 4 denotes white/light-blue 
layering characteristic of very small and irregular carbonate crystals separated from a region of larger but irregular crystal polyhedral shown by the SEM insert. Many of the larger crystal platelets in the SEM insert in Fig. 4 exhibit hexagonal edge/facet features where the internal angle between edges is $120^{\circ}$. In the small crystal regime particles range from $<0.5 \mu \mathrm{m}$ to $\sim 2.5 \mu \mathrm{m}$, while in the larger prismatic particle regime the crystal platelets vary in size from $\sim 2 \mu \mathrm{m}$ to $15 \mu \mathrm{m}$. Structural color in the blue portion of the optical spectrum results for particles $\leq 500 \mathrm{~nm}$, primarily in the small particle layer portion.

In contrast to the pearl interior (prismatic) layer structure, the pearl surface exhibits regular terracing of polygonal tablets or tile-like crystal polygons, either rectangular-like or hexagonal-like, usually forming angles of $120^{\circ}$ at their juncture as shown by the arrow in Fig. 5 . In addition, Fig. 5 shows the nucleation and growth of these crystal carbonate tiles or tablets at varying locations over the terraced surface steps. The EDS spectrum insert illustrates the calcium carbonate chemistry of the surface with no measurable impurities.

Figures 6 and 7 compare the pearl interior calcium carbonate crystal polymorphs with those on the surface. The corresponding XRD spectra indicate that essentially all of the crystals near the midsection between the seed graft area and the surface are calcite (Fig. 7a), while the pearl surface is composed almost entirely of aragonite tiles. The XRD spectra exhibit a larger fraction of aragonite as the layers approach the surface. Habermann et al. ${ }^{15}$ noted that Chinese tissue-graft freshwater pearls such as those illustrated herein contain relatively large proportions of calcite crystals in the pearl interior in contrast to natural freshwater pearls from the Mississippi River, while Jacobs et al. ${ }^{16}$ and $\mathrm{Li}$ et al. ${ }^{17}$ noted that calcium carbonate in cultured freshwater pearls is present mainly as aragonite, including for the mussel species in this study.

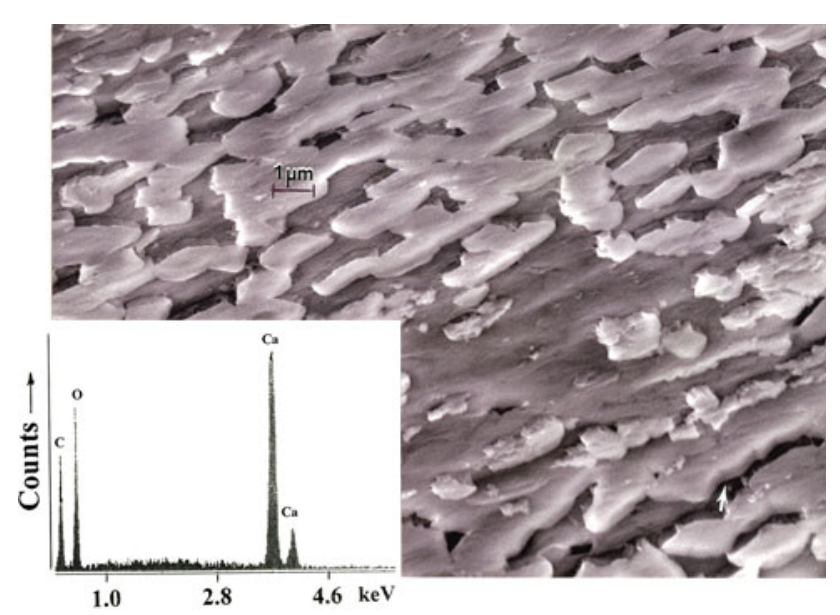

Fig. 5. Spherical pearl surface area observed in the SEM showing irregular aragonite polygonal tiles having constant thickness of $\sim 400 \mathrm{~nm}$. The insert shows an EDS Ca-C-O spectrum.
In the more regular development of crystal tiles or tablets such as the pearl surface as illustrated in Figs. 5 and $6 \mathrm{~b}$, especially aragonite tiles and tile terraces, there is some variance from shell development because, in shells, the curvature is characterized by a large concave radius while for the pearl surface the curvature is characterized conversely by a small convex radius. In the case of shell formation it is well established that the organic matrix located between the aragonite layer plates or tablets, often referred to as the intertabular matrix, controls the formation of the calcium carbonate crystal polymorphs and dictates when and where they nucleate and stop growing, their expansion and positioning, and adjustments in growth where appropriate. $^{12,13,18}$ This is therefore a genetically directed nucleation process rather than a crystallographically directed nucleation process as in epitaxial nucleation and growth of single crystals. For nacre growth in bivalve shells, holes or porous regions exist in the intertubular organic matrix, and nucleation for a given stack of crystals occurs by mineral bridges through the matrix, as recently illustrated for abalone nacre by Meyers et al. ${ }^{9}$

When the mantle seed is inserted too close to the mother of pearl in the shell surface, the growing pearl in contact with the nacre surface will flatten, altering the pearl curvature as illustrated on comparing two

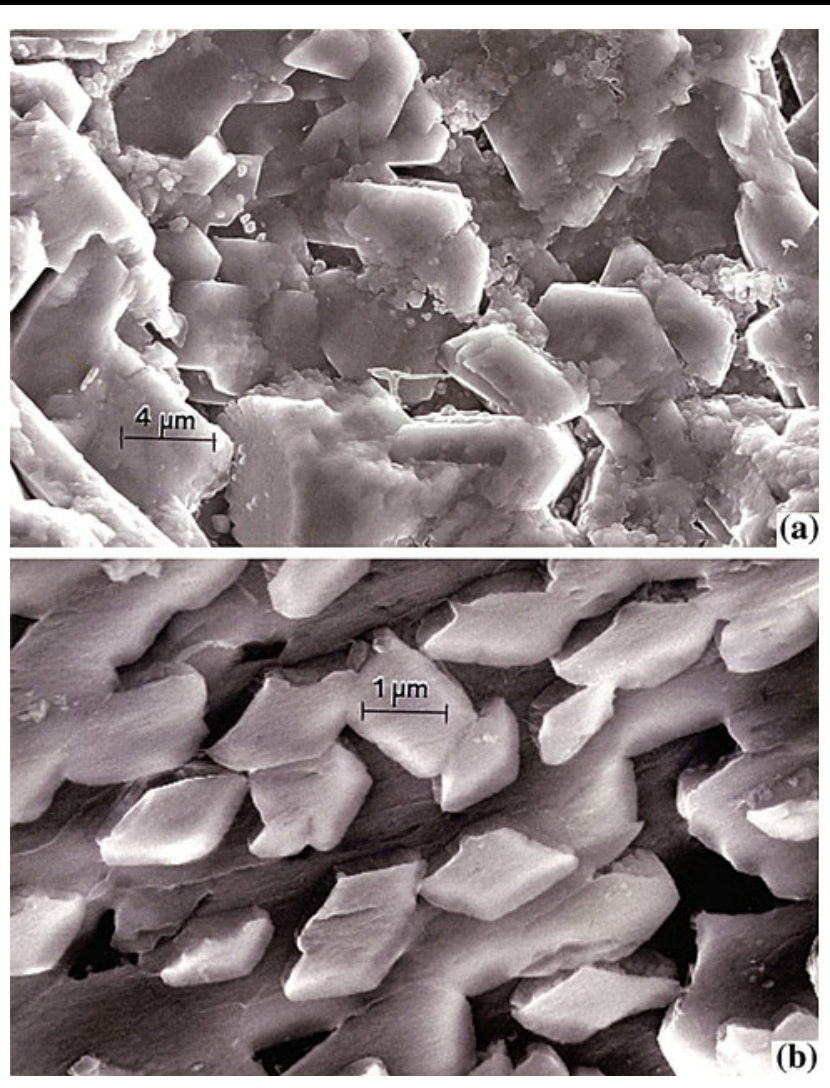

Fig. 6. Comparative SEM views for pearl internal layer crystals (mostly calcite) (a) and external surface crystals (mostly aragonite) (b) corresponding to Figs. 4 and 6, respectively 
comparable pearl morphologies in Fig. 8. As evidence of, or an example of, the effect that this intervention has on normal pearl growth and biomineralization, the XRD spectrum of Fig. 9 shows that a flattened
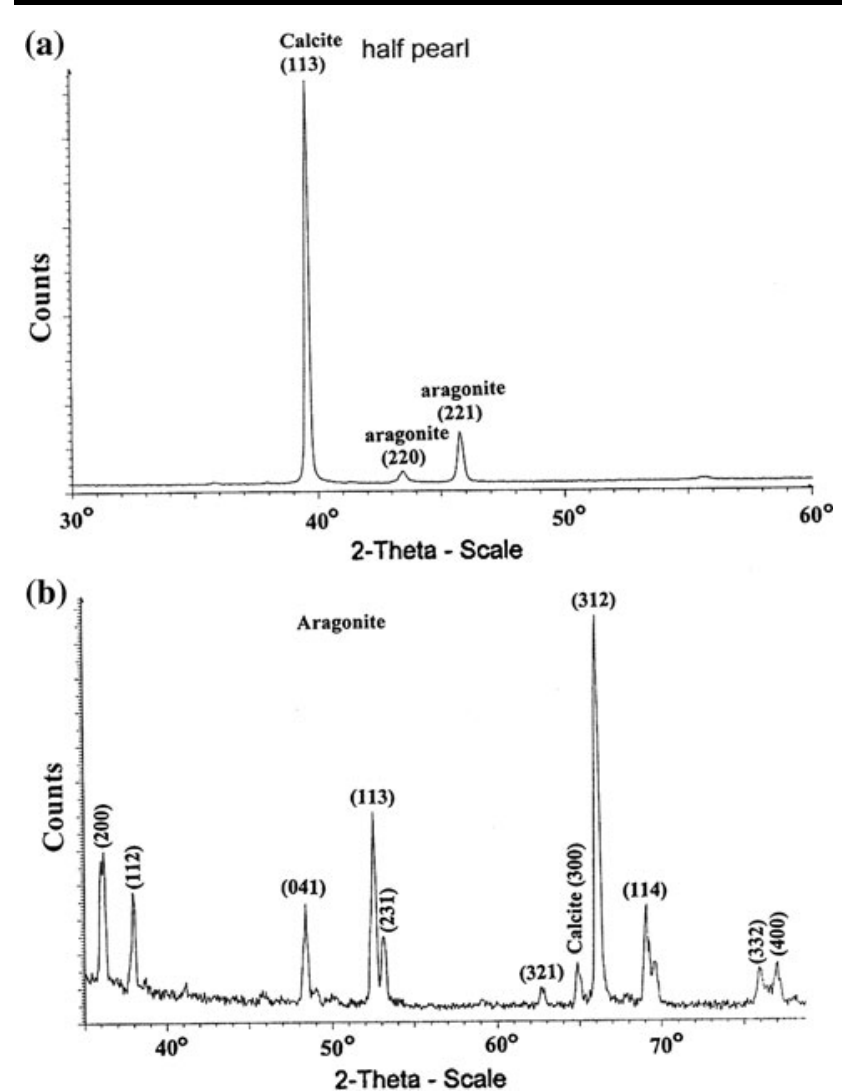

Fig. 7. Comparative XRD spectra corresponding to (a) internal pearl layer crystal structure, and (b) external pearl surface structure pearl surface as in Fig. 8b contains an appreciable calcite crystal content in contrast to the normal, curved pearl surface in Fig. $8 \mathrm{a}$, and as shown in the corresponding XRD spectrum in Fig. 7b.

The implications for crystal surface structure for the mantle-tissue-graft cultured pearls in Fig. 4 are that the dark-blue layer zone extends roughly $800 \mu \mathrm{m}$. This should have roughly 1600 uniform aragonite tablet or tile layers with thicknesses of $300-500 \mathrm{~nm}$, oriented somewhat prominently in the $c$-axis direction, corresponding to structural color in the far blue portion of the optical spectrum. Figure 10 confirms this very regular tile/terrace structure for hexagonal-like aragonite polygons. A magnified view of the nacre layer structure in Fig. 10 is shown in Fig. 11, which shows a very uniform aragonite tile thickness of $\sim 400 \mathrm{~nm}$, although the much thinner interlamellar or intertabular organic layer $(\sim 20-40 \mathrm{~nm})$ is not discernible.

It is of interest to note in Figs. 5 and 10 that the aragonite tiles composing the pearl mesolayers have

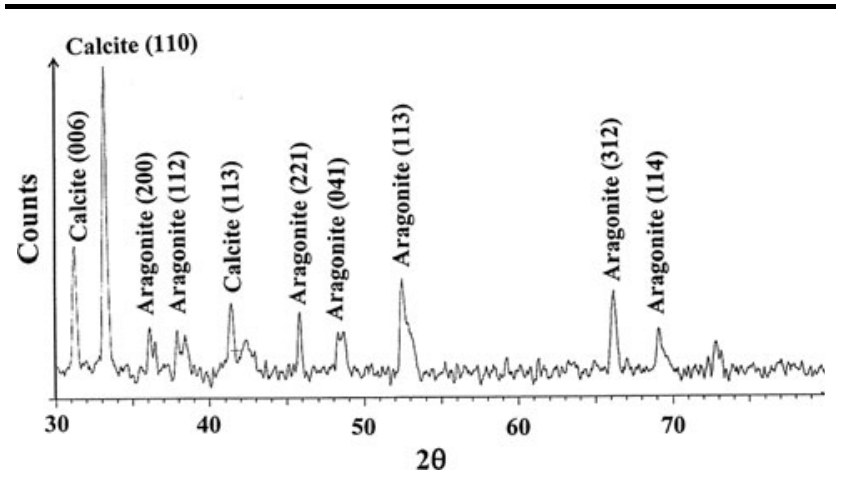

Fig. 9. XRD spectrum for flat pearl surface area as in Fig. $8 \mathrm{~b}$.

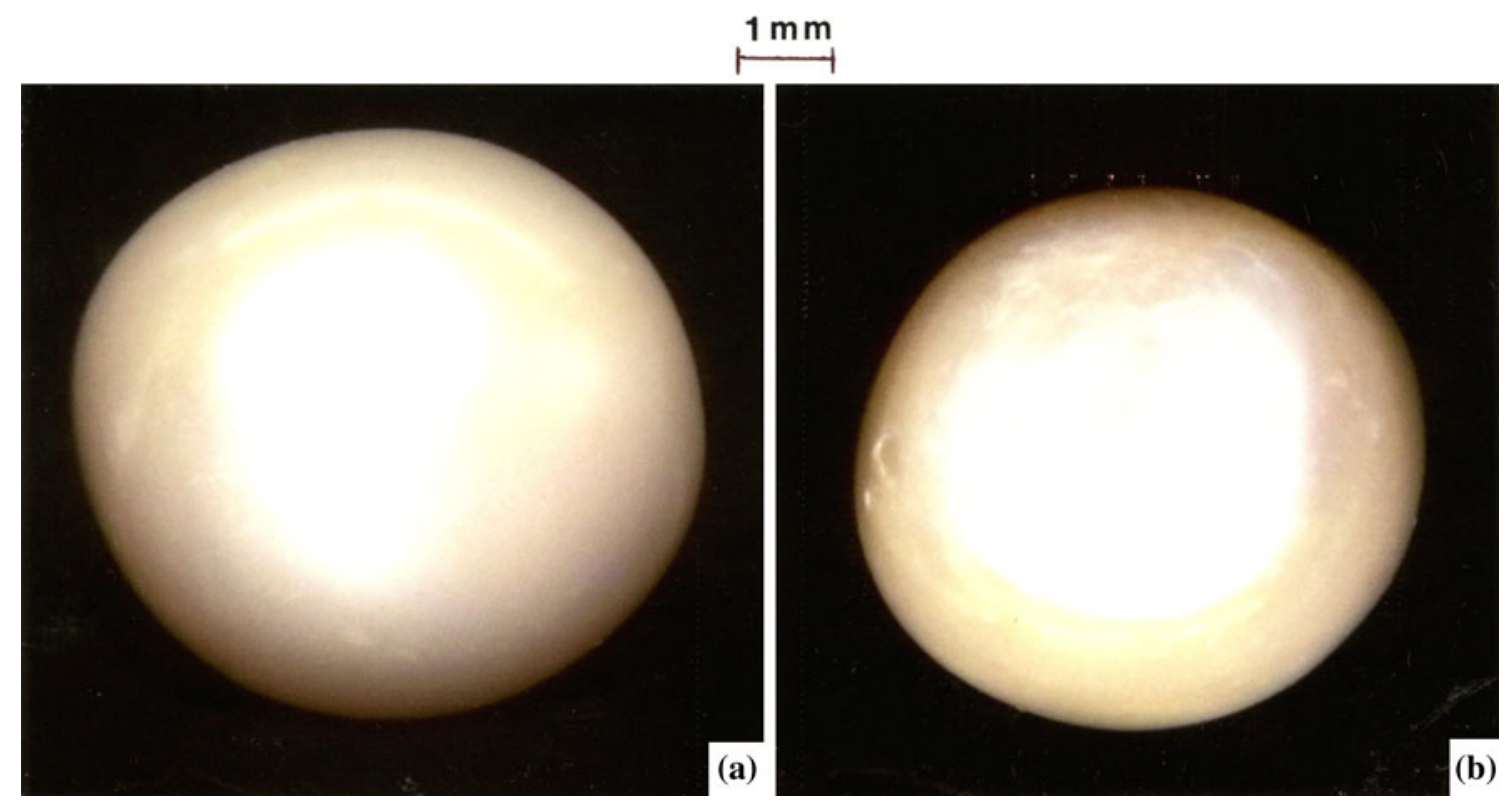

Fig. 8. Slightly irregular freshwater pearls. (a) Nearly spherical pearl having size commensurate with the half-section in Fig. 4. (b) Pearl with flattened surface region. 


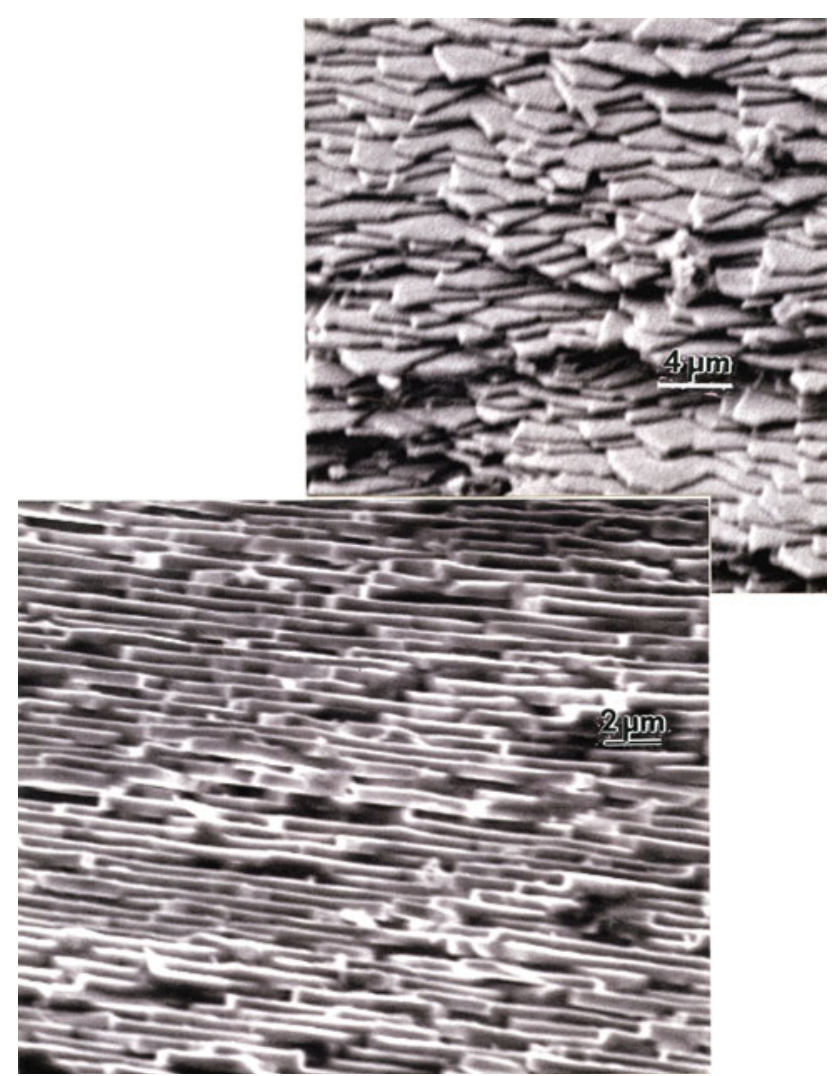

Fig. 10. SEM images at different angles of observation on a cultured pearl curved surface region showing aragonite mesolayers and polygonal tile edges. Magnification markers are 4 and 2 microns, respectively.

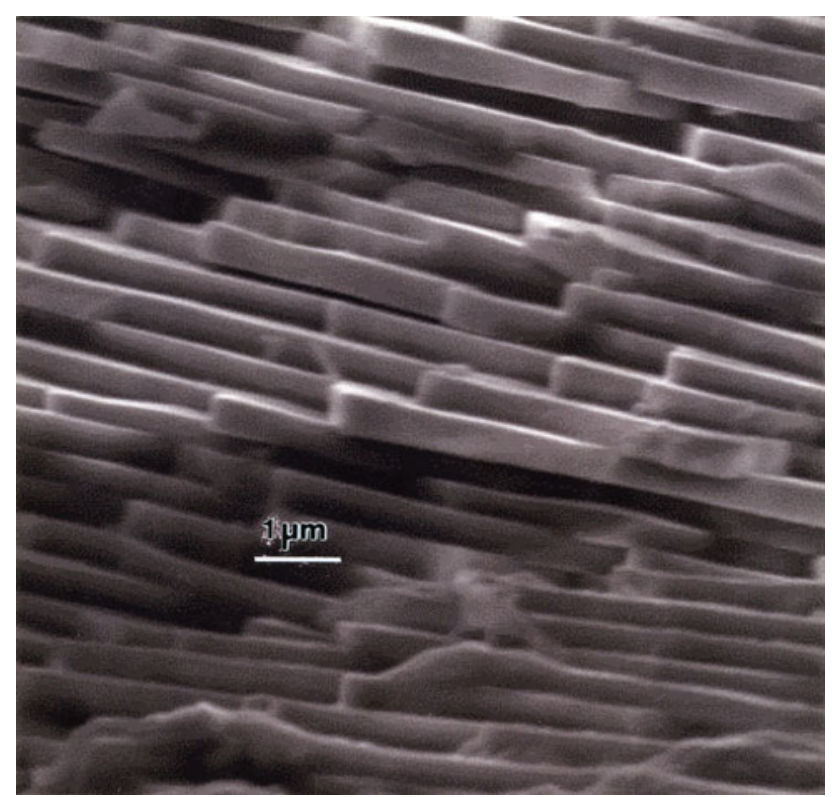

Fig. 11. SEM magnified view for aragonite tile mesolayers in the surface region of a round, cultured freshwater pearl. Magnification marker is 1 micron.

the same structure as abalone shell nacre described recently by Meyers et al., ${ }^{9}$ but the individual tile polygons are only about half the size $(\sim 3-4 \mu \mathrm{m})$.
This is probably due to the curvature variation and accommodation. Although the organic matrix is not discernible, the organization of the aragonite tile mesolayers in Fig. 10 in particular is indicative of the origin of the high compressive strength and hardness of these cultured pearls as previously noted by Meyers et al. ${ }^{9}$ for shell nacre.

\section{CONCLUSIONS}

It is easy to see why Chinese cultured freshwater pearls have completely dominated the cultured pearl market worldwide. They are, from a microstructural (microcrystalline) perspective, identical to natural pearls, including both seawater and freshwater pearls. As a consequence of the highly symmetrical aragonite crystal mesolayer freshwater pearl structure, the cultured, freshwater pearls maintain a requisite luster, and when round, are of the best gem quality in the context of the commodity jewelry market. The cultured pearl industry is the quintessential example of by-product synergism and emulates best-practice business strategies which produce superior products at reduced prices. It also illustrates the significant advances as a consequence of biological intervention.

\section{ACKNOWLEDGEMENTS}

This research was supported in point by a Mr. and Mrs. MacIntosh Murchison Endowment at the University of Texas at El Paso. We are grateful to C. C. Zhong of the Seeds Pearl Co. Ltd., Zhuji City, China for provision of cultured pearls and exposure to the cultured pearl industry.

\section{REFERENCES}

1. E.N. Carpi, B. Pokroy, P.L. Lee, J.P. Quintana, and E. Zolotoyabko, Acta Cryst. B: Struct. Sci. 61, 129 (2005).

2. N. Watanabe, J. Ultrastruct. Res. 12, 370 (1965).

3. H.A. Lowenstam and S. Weiner, On Biomineralization (New York: Oxford University Press, 1989).

4. Lia Addadi, D. Joester, F. Nudelman, and S. Weiner, Chem. Eur. J. 12, 980 (2006).

5. G. Mayer and M. Sarikaya, Exp. Mech. 42, 395 (2002).

6. J.D. Currey, Proc. R. Soc. Lond. 196, 443 (1977).

7. A.P. Jackson, J.F.V. Vincent, and R.M. Turner, Proc. R. Soc. Lond. B 234, 415 (1988).

8. R. Menig, M.H. Meyers, M.A. Meyers, and K.S. Vecchio, Mater. Sci. Eng. A 297, 203 (2001).

9. M.A. Meyers, A.Y.-M. Lin, P.-Y. Chen, and J. Muylo, J. Mech. Behav. Biomed. Mater. 1, 76 (2008).

10. F. Marin and G. Luquet, Comtes Rendas Palevol 3, 469 (2004).

11. F. Marin and G. Luquet, Mater. Sci. Eng. C 25, 105 (2005).

12. D. Jackson, C. McDougall, B. Woodcroft, P. Moase, R. Rose, R. Kube, M. Reinhardt, and D. Rokhsar, Mol. Biol. Evol. 27, $591(2010)$

13. F.H. Wilt, C.E. Killian, and B.T. Livingston, Differentiation 71,237 (2003).

14. F. Nudelman, B.A. Gotliv, L. Addadi, and S. Weiner, J. Struct. Biol. 153, 176 (2006).

15. D. Habermann, A. Banerjee, J. Meijer, and A. Stephan, Nucl. Instrum. Methods Phys. Res. B181, 739 (2001).

16. D.E. Jacob, A.L. Soldafi, R. Wirth, J. Huth, U. Wehmeister, and W. Hofmeister, Geochim. Cosmochim. Acta 72, 5401 (2008).

17. J. Li, G. Wong, Z. Bai, and G. Yue, Mol.Ecol. Notes 7, 1357(2007)

18. S.M. Porter, Science 316, 1301 (2007). 